\title{
Corrigendum: Limits on Monolingualism? A Comparison of Monolingual and Bilingual Infants' Abilities to Integrate Lexical Tone in Novel Word Learning
}

\author{
Leher Singh *, Felicia L. S. Poh and Charlene S. L. Fu \\ Department of Psychology, National University of Singapore, Singapore, Singapore
}

Keywords: lexical tone, phoneme discrimination, infant speech perception, Mandarin Chinese, word learning

\section{A corrigendum on}

Limits on Monolingualism? A Comparison of Monolingual and Bilingual Infants' Abilities to Integrate Lexical Tone in Novel Word Learning

by Singh, L., Poh, F. L. S., and Fu, C. S. L. (2016). Front. Psychol. 7:667. doi: 10.3389/fpsyg.2016.00667

\section{OPEN ACCESS}

Edited and reviewed by: Miquel Simonet,

University of Arizona, USA

${ }^{*}$ Correspondence:

Leher Singh

psyls@nus.edu.sg

Specialty section: This article was submitted to

Language Sciences, a section of the journal

Frontiers in Psychology

Received: 18 May 2016 Accepted: 16 June 2016 Published: 30 June 2016

Citation:

Singh L, Poh FLS and Fu CSL (2016)

Corrigendum: Limits on Monolingualism? A Comparison of Monolingual and Bilingual Infants' Abilities to Integrate Lexical Tone in

Novel Word Learning.

Front. Psychol. 7:992.

doi: 10.3389/fpsyg.2016.00992
Reason for Corrigendum:

Due to an oversight by the authors, Figures 3, 4 were switched. Figure 3 displays the results of Experiment 1 (Mandarin-English bilingual infants) and Figure 4 displays the results of Experiment 2 (Mandarin monolingual infants). The authors apologize for this mistake. This error does not change the scientific conclusions of the article in any way.

\section{FUNDING}

This research was supported by a grant from the National University of Singapore, Singapore to LS (HSS R-581-000-178-646), to a Ministry of Education Tier 1 Academic Research Fund (FY2013-FRC2-009) grant to LS, and to a grant from the Singapore Children's Society to CF.

\section{ACKNOWLEDGMENTS}

We are grateful to Aloysia Tan, Desirene Poon, and Xian Hui Seet for assistance for assistance with stimulus recordings and to Cathi Best, Janet Werker, and Chris Fennell for methodological guidance.

Conflict of Interest Statement: The authors declare that the research was conducted in the absence of any commercial or financial relationships that could be construed as a potential conflict of interest.

Copyright (c) 2016 Singh, Poh and Fu. This is an open-access article distributed under the terms of the Creative Commons Attribution License (CC BY). The use, distribution or reproduction in other forums is permitted, provided the original author(s) or licensor are credited and that the original publication in this journal is cited, in accordance with accepted academic practice. No use, distribution or reproduction is permitted which does not comply with these terms. 


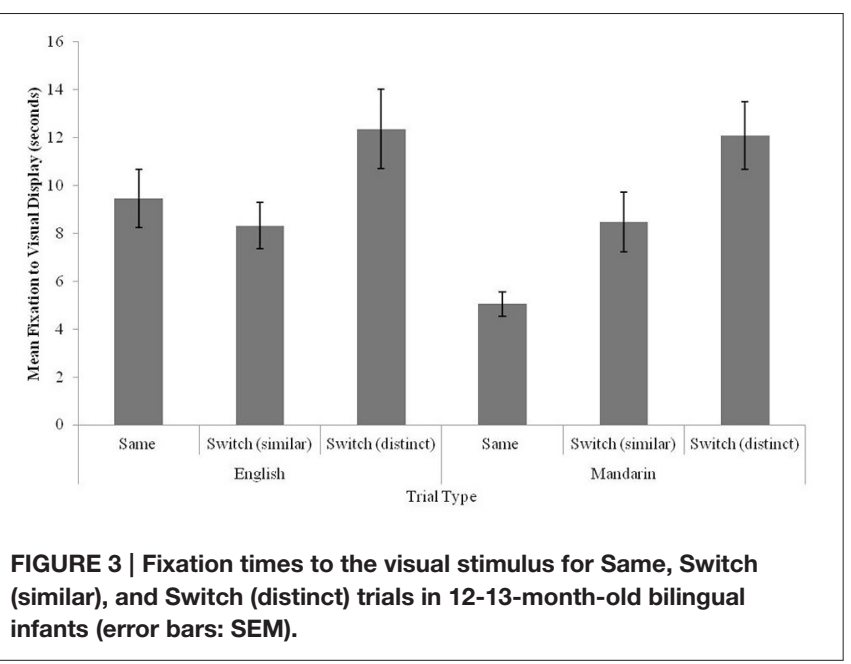

(similar), and Switch (distinct) trials in 12-13-month-old bilingual infants (error bars: SEM).

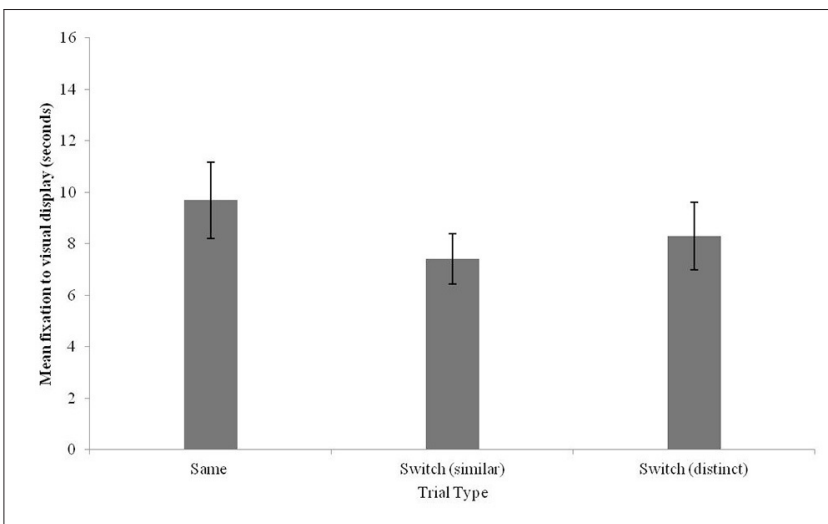

FIGURE 4 | Fixation times to the visual stimulus for Same, Switch (similar), and Switch (distinct) trials in 12-13-month-old Mandarin monolingual infants (error bars: SEM). 